\title{
Expoliación y violación de los derechos humanos en territorio mapunche. Cartas del padre Sigifredo, Misión de Panguipulli, año $1905^{\star}$
}

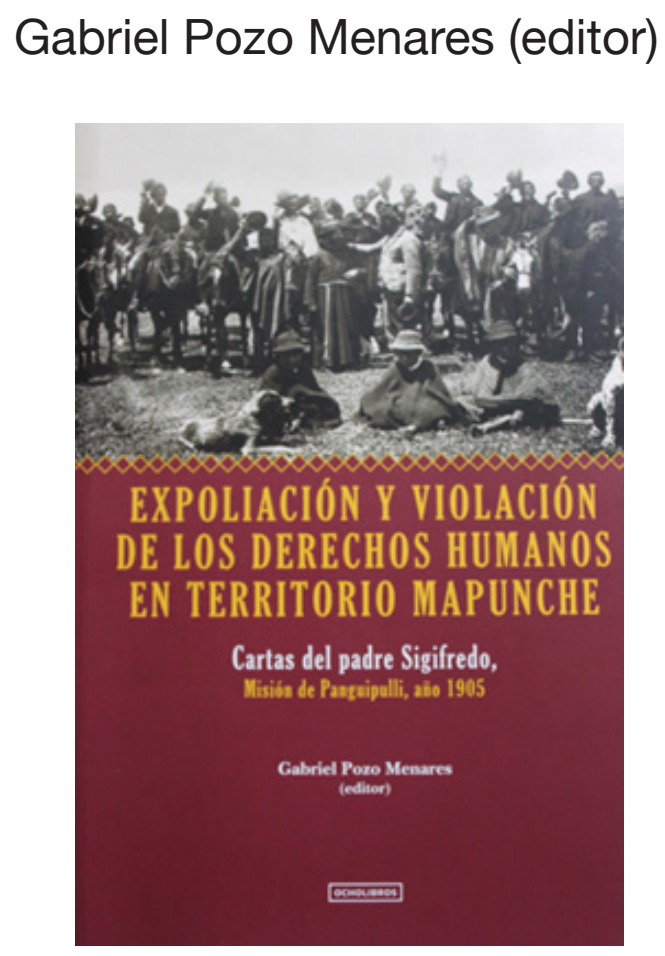

\section{LUIS BERGER ${ }^{\star \star}$}

La constitución de la propiedad de la tierra ha sido una de las problemáticas centrales en torno a las cuales se ha desarrollo la historiografía sobre el espacio territorial del sur de Chile. A partir de su

2018. Santiago: Editorial Ocho Libros. 532 páginas.

** Profesor de Historia y Ciencias Sociales. Magíster en Pensamiento Contemporáneo. Universidad Austral de Chile. Correo electrónico: luis.berger.venegas@gmail.com. 
estudio se han podido esclarecer los distintos procesos que sirvieron como base estructural para la configuración de nuestra sociedad rural sobre el antiguo territorio mapuche. Sin embargo, esta no ha sido una historia enfocada en descubrir en la raíz de lo que somos un principio de respeto e integración, sino más bien uno de injusticia y discriminación, en el cual la violencia desempeñó un papel fundamental como medio para imponer un determinado régimen social en torno a la tenencia de la propiedad de la tierra.

Como se sabe, la historia moderna del proceso de constitución de la propiedad de la tierra en el sur del país, se inicia a partir del hito que significó la conquista del antiguo territorio mapuche de la Araucanía, durante la segunda mitad del siglo XIX. Dentro de este proceso las políticas de colonización nacional fueron el principal medio utilizado por el Estado para constituir la propiedad de la tierra, estableciendo un determinado patrón de distribución y explotación del territorio recién conquistado, entregando su tenencia a una sociedad de colonos nacionales y extranjeros, la cual debió convivir junto a los miembros de la otrora sociedad mapuche, para entonces reducida y fragmentada como campesinos pobres. Desde un comienzo dicha sociedad rural debió lidiar con los llamados "propietarios de papel", individuos inescrupulosos que, invocando todo tipo de títulos, proclamaban su derecho privado sobre vastas zonas de territorio, originando graves enfrentamientos y cruentas disputas por el dominio de la propiedad de la tierra. Semejante escenario tendría lugar dentro de un contexto rural marcado por una fase de transición de la propiedad de la tierra, en el cual las relaciones sociales en torno a su tenencia no se encontraban del todo regularizadas, siendo su dominio un derecho legal aún susceptible de ser apropiado y disputado por distintos medios, situación que alcanzó su mayor expresión y crudeza en los casos en contra de mapuches.

En este sentido, la obra aquí reseñada, Expoliación y violación de los derechos humanos en territorio mapunche. Cartas del padre Sigifredo, Misión de Panguipulli, año 1905, constituye un significativo aporte documental a la comprensión histórica de este complejo escenario social surgido en torno a la tenencia de la propiedad de la tierra, así como de los crímenes y atropellos cometidos en contra de la sociedad mapuche a manos de colonos nacionales y extranjeros en el sur del país. Específicamente, esta obra recoge las cartas escritas por el padre misionero de la Orden de los Capuchinos bávaros alemanes Sigifredo Frauenhäusl, con el propósito de "poner a disposición de un público 
amplio las evidencias que demuestran el proceso de usurpación territorial, la expoliación y la violación de derechos humanos que afectó a la sociedad mapuche a principios del siglo XX" (Pozo, 2018: 27).

En términos formales, la propuesta de esta obra se compone de dos partes. La primera se preocupa de exponer la documentación original del Libro Copiador de Cartas elaborado por el padre Sigifredo, conformado por 501 folios con un total de 384 cartas ordenadas de manera cronológica y organizadas según diferentes criterios que contribuyen a su estudio, incluyendo un índice onomástico y toponímico con el objetivo de ayudar a profundizar en los nombres de las personas y sectores territoriales implicados en la lectura de las cartas. La segunda se compone de siete ensayos que profundizan de distinta manera en el análisis del testimonio del padre Sigifredo y en el contexto en el que se desarrollaron los acontecimientos. A esto debemos agregar además de un anexo con fotografías que ilustran diferentes escenas de la vida cotidiana al interior de la Misión de Panguipulli para comienzos del siglo XX.

El testimonio del padre Sigifredo nace de las dificultades con que la conquista espiritual de la Araucanía y su misión evangelizadora se encontraron en el escenario social de la propiedad de la tierra para comienzos del siglo XX. En efecto, como parte de un grupo de misioneros europeos llegados a nuestro país con el objetivo de participar en la "civilización" de la población originaria, el padre Sigifredo debió enfrentar la difícil situación que aquejaba a la sociedad mapuche de Panguipulli, como consecuencias del robo de sus tierras. En una carta fechada el 23 de enero de 1905, el padre Sigifredo relata: "la dificultad mas grande en esta Misión forma la defensa de los indios contra el despojo de sus campos. Como se trata para los indios sobre vivir ó no vivir, creo yo que incumbe al misionero la grave obligación hacer valer toda su autoridad para que no perezcan los indios. Preocupados por el constante temor de ser arrojados de sus posesiones casi no dan cabida á la enseñanza religiosa" (Pozo, 2018: 41). En pocas palabras, a juicio del misionero alemán, sólo una vez solucionada la cuestión de la propiedad de la tierra en la zona, se podría continuar con la enseñanza religiosa.

De este modo, con la intención de asumir la defensa pública de la sociedad mapuche de la zona de Panguipulli, el padre Sigifredo escribió por años numerosas cartas dirigidas al Prefecto Apostólico, al Presidente de la República, al Inspector General de Tierras y Colonización, al ministro de Colonización, al Subinspector de la Colonización, al Protector 
de Indígenas, al Protector fiscal, al Intendente, al Juez de Letras, así como a varios jueces de distrito y subdelegaciones, con el propósito de denunciar los abusos y atropellos cometidos por parte de colonos nacionales y extranjeros en contra de mapuches. En ellas el padre Sigifredo describió con detalle los distintos "medio legales" utilizados por algunos personajes de la zona, con el fin de apropiarse de las tierras mapuches, exigiendo la restitución de las tierras usurpadas y el respeto a la legislación especial promulgada con el objetivo de prohibir y limitar el acceso de los particulares a las tierras indígenas (1893), pidiendo al mismo tiempo por un rápido proceso de radicación, el cual permitiría a los mapuches obtener el reconocimiento legal sobre el deslindes de sus propiedades (títulos de merced). Asimismo, en sus cartas, el padre Sigifredo llamó la atención sobre la responsabilidad de las autoridades en este problema, quienes a partir de su intervención o indiferencia se hacían participes en el robo de tierras. En efecto, como nos cuenta en sus cartas, muchos de los casos denunciados por el capuchino alemán fueron ordenados por el propio Juez de Letras de Valdivia y ejecutados de manera violenta por las fuerzas de carabineros, como resultado de demandas judiciales iniciadas muchas veces sobre la base de presiones y procedimientos fraudulentos:

"Hace ahora 8 años asesinó Joaquin Mera á la India Nieves Ayñamco con el único fin de apoderarse de la posesión de ella, denominada Pinco, fundo contiguo con sus demas terrenos usurpados. Mera fue reducido á prisión, permaneciendo 6 meses en la cárcel. Salió en seguida de la cárcel con fianza, sin que hasta ahora haya sido incomodado el criminal. Las 3 hijas de Nieves Ayñamco siguieron con el juicio contra Mera, pero la justicia de Valdivia no ha hecho actualmente nada. Mera quedó dueño del fundo Pinco y las tres hijas tienen que sufrir hasta la fecha las venganzas del bárbaro Joaquin Mera y viven en extrema pobreza. Una de ellas, Manuela Vera, fue colgada varias veces por Mera en un árbol y azotada. Un dia las mandó tomar "presas" á las tres hermanas y las llevó á la casa en Manguedehue (...) Estando todas en la casa de Joaquin Mera, las obligó este de renunciar los derechos que pudieran tener en el fundo Pinco. Las indias afligidas por las amenazas de Mera renunciaron de su posesión delante de un juez de distrito que también para este fin fue llamado á Manguedehue" (Pozo, 2008: 173-174).

Por medio de testimonios como este, las cartas de padre Sigifredo nos ofrecen valiosa información sobre la situación histórica que se vivía para ese entonces en torno a la propiedad de la tierra en el sur del 
país, la cual sirve de inspiración para los siete ensayos que componen la segunda parte de esta obra, dando cuenta de temas tan diversos, pero siempre interrelacionados, como son las cualidades personales del padre Sigifredo y su trayectoria en la defensa de la sociedad mapuche de Panguipulli, la ocupación territorial por parte de los colonos extranjeros y la formación de la sociedad rural, la violación de los derechos humanos y las prácticas de usurpación de tierras indígenas, la institucionalidad política y las características del sistema judicial en la zona, así como otras temáticas vinculadas a la vida cotidiana dentro de la Misión.

A pesar de no haber sido del todo consciente sobre el proceso histórico en el cual se encontraba inmerso, la forma en que el padre Sigifredo describió los hechos de los que fue testigo nos revelan con gran lucidez el drama social originado en torno a la tenencia de la propiedad de la tierra el sur del Chile para comienzos del siglo XX. En este sentido, como señala el propio autor a cargo de la edición de esta obra, particularmente destacan dos expresiones utilizadas por el capuchino alemán y que retratan con gran precisión las condiciones objetivas y subjetivas que definieron el proceso de despojo de la sociedad mapuche de Panguipulli. Por un lado, la expresión de "expoliación", entendida como la acción de apropiarse de forma violenta e injusta de los bienes de otra persona, recoge de manera fiel la naturaleza criminal y terrorista de las acciones emprendidas en contra de la sociedad mapuche, con el único fin de arrebatarles sus tierras ancestrales. Por otro lado, la expresión de "derechos de la humanidad", entendida como el reconocimiento universal de la dignidad de las personas como un derecho fundamental, apunta de manera precisa a la naturaleza del daño infligido, el cual se relaciona con la deshumanización y negación histórica de un grupo específico de la sociedad chilena, con el único fin, nuevamente, de arrebatarles sus tierras. En conjunto, ambas expresiones recogen la brutalidad detrás del proceso de desposesión material de un pueblo definido culturalmente por su relación con la tierra y, por tanto, el quiebre de su propio principio ontológico como "mapu-che" o "gente de la tierra".

Desde una perspectiva historiográfica, el testimonio del padre Sigifredo nos invita a revisar nuestra historia oficial a la luz de los hechos de violencia y discriminación que han marcado a ciertos grupos de la sociedad chilena, invitándonos a tomar conciencia sobre los efectos epistemológicos que ciertas categorías tienen al momento de explicar determinados procesos, tal como "colonización", "pacificación" u "ocupación" de la Araucanía, funcionando como verdaderos eufemismos 
historiográficos, los cuales no hacen otra cosa que encubrir el abuso y la violencia que estos procesos involucraron. Es más, en muchos casos estas categorías han contribuido a legitimar una mirada civilizatoria de los distintos procesos de expansión nacional sobre el antiguo territorio mapuche durante el siglo XIX, insistiendo en mostrar una visión idílica de aquellos sucesos que permitieron a nuestro país acumular grandes riquezas, financiar importantes obras públicas e impulsar la anhelada modernización capitalista. Sin embargo, como bien los demuestran las cartas del padre Sigifredo, los métodos utilizados por estos procesos fueron cualquier cosa menos idílicos, y de ellos, paradójicamente, brotaron los peores vicios del "mundo civilizado".

En definitiva, como queda demostrado en la obra aquí reseñada, el testimonio del padre Sigifredo constituye una valiosa fuente documental para dilucidar el papel que la violencia social hacia el pueblo mapuche ha desempeñado en la estructuración del orden social en torno a la tenencia de la propiedad de la tierra para inicios del siglo XX, quedando su contenido abierto a la interpretación que distintas investigaciones puedan hacer de él, de manera de seguir aportando al conocimiento de una época en que las disputas por el dominio de la propiedad de la tierra definieron la historia social del sur de Chile.

\section{Bibliografía}

Pozo Menares, Gabriel (editor). 2018. Expoliación y violación de los derechos humanos en territorio mapunche. Cartas del padre Sigifredo, Misión de Panguipulli, año 1905. Santiago: Editorial Ocho Libros. 